\title{
OBITUARY: Miloslav Jiřina
}

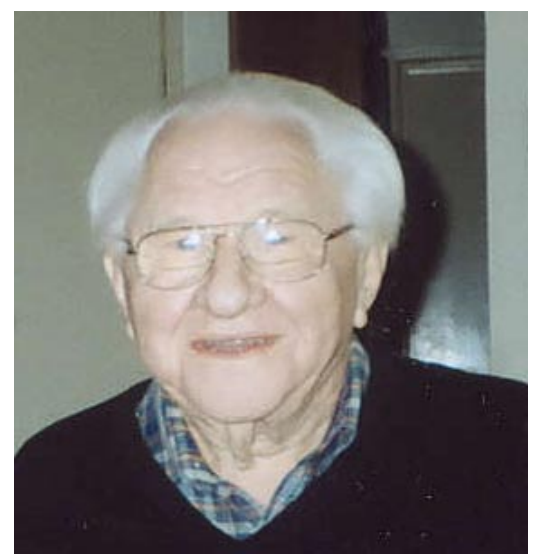

Miloslav Jiřina, 1927-2011

Miloslav's father, as a Czech citizen of the Austro-Hungarian Empire at the outbreak of World War I, was conscripted to fight in Russia. He eventually joined units of Czech prisoners of war fighting for an independent Czech state. These were the Czech 'legions', which fought, after the Bolshevik Revolution, with the Whites against the Bolsheviks. After the Whites were defeated the Czech legionaries returned home by way of Siberia and Canada, and were celebrated as heroes in the Czechoslovak Republic (established in 1918) .

Miloslav's mother's family had lived in Slovenia, then also a part of Austria-Hungary. After returning to their homeland, which had become the Republic of Czechoslovakia, Miloslav's mother became a successful tailor dressmaker whose 'salon' had several employees. Miloslav's parents, for the times, were married relatively late in life. His mother, a gentle woman, was 36 when Miloslav, her second child, was born on 6th November 1927.

Miloslav's parents bought a modest house in Klatovy, where they lived with their extended family; Miloslav's father became a civil servant. In 1938, with war looming, he was transferred to Trebon where he was unknown. This was fortunate, since after the German occupation of Czechoslovakia, known former Czech legionaries like his father were sent to concentration camps. Had he been in Klatovy, where he had been prominent as head legionary, that would have been his fate.

Miloslav had a happy childhood. His elementary school education was in Klatovy.

His wife to be, the-then Jarmila Skachova, remembers Milo (as he was familiarly called) from April 1939. Her Czech family was expelled from Slovakia after 15th March 1939, when Slovakia became a Slovak State. Both Miloslav and Jarmila were in the same class of year 1 in the 'Realgymnasium' in Trebon, where Miloslav spent his high school years, matriculating in 1946. He then enrolled in Prague's Charles University (Karlova Universita, Praha) as a student of mathematics and mathematical statistics, where he was an undergraduate from 1946 to 1950.

The relationship between Miloslav and Jarmila deepened in their matriculation year, and later when both were students at Charles University. Jarmila was a student in the Faculty of

A version of this obituary will run in Applications Math. 
Philosophy, and became a teacher. On 29th January 1949 they married and a daughter, also named Jarmila, was born to them.

Between 1950-1952 Miloslav worked as Scientific Officer in the mathematical department of an electrical engineering research institute: the Tesla Electronic, Praha. His main activity was statistical quality control, in both theoretical research and practical work in factories.

Miloslav's postgraduate studies in stochastic processes at Charles University were carried out over the years 1953-1955. In 1952 he was awarded the RNDr (Rerum Naturalium Doctor) which he later described as a degree by thesis, beween a Master's and a PhD in Australian terms. Such pre-war system degrees were abolished by the government for part of the 1950s, and a new degree was introduced. This was the CSc (Candidate of Sciences), presumably to parallel the Soviet 'Kandidat Nauk'. Miloslav was awarded this degree in 1956; he described the CSc as the exact equivalent of the PhD.

During the period 1955-1968, Miloslav was a Research Scientist in the Department of Mathematical Statistics and Probability at the Mathematical Institute of the Czechoslovak Academy of Sciences in Prague. In about 1965 a new degree and title were created for the highest level of scientific achievement, the DrSc (Doctor of Sciences). Miloslav achieved this award in 1967: it was, and remains, a rare honour. It is likely that Jiřina (1966), published in the Rozpravy of the Czechoslovak Academy, contains the material which won him that award.

During his Prague years Miloslav was able to accept invitations to East Germany, Poland, Rumania, West Germany, England, and the Sorbonne to lecture about his research. He spent more than two months in 1958 in Moscow and Leningrad on an exchange program, and was gratified to be able to talk to A. N. Kolmogorov. He spent several weeks in 1965 as a participant in the prestigious 5th Berkeley Symposium.

Miloslav's publications contain a body of outstanding contributions to the theory of branching processes. Revival of this theory in the 20th century was largely initiated by a paper of Kolmogorov (1938), followed after the war by that of his student Yaglom (1947). Yaglom proved asymptotic conditional limit theorems in the usual setting of discrete (integer-valued) time (nonoverlapping generations), in all three cases $m<1$ (subcritical), $m=1$ (critical), and $m>1$ (supercritical), where $m$ is the mean number of offspring per individual. All were proved under (at least) second moment conditions on the offspring distribution. Then followed two large research/review papers by Sevast'yanov (1951), essentially for continuous time, and Harris (1951), largely in discrete time with a partial generalization to the multitype case (that is, several kinds of particle). Here $m$ is replaced by a 'regular' nonnegative mean matrix $M$, where criticality is measured by whether $\rho<1, \rho=1$, or $\rho>1$, where $\rho$ is the Perron-Frobenius eigenvalue of $M$. Jiřina (1957), taking his lead from all the above papers, and using the theory of nonnegative matrices as set out within Gantmacher (1953), generalized Yaglom's theorem to the multitype subcritical case, doing this for continuous time as well. It seems likely that the publication of this paper helped lead to his sojourn in Moscow in 1958.

As it turns out, Yaglom's limit distribution in the subcritical case is a univariate manifestation of a quasistationary distribution, a topic on which one of us (ES) was working on in 1964 for his MSc under the direction of the other (JD). That year was the beginning of our knowledge of Miloslav's work, brought about by Jiřina (1957) being cited in the now classical monograph of Harris (1963), which had just appeared.

ES continued to work in part during his PhD years (1965-1968) at the Australian National University (ANU) on relaxing the second-order conditions of Yaglom's (univariate) theorems. Eventually, he became interested in univariate discrete-time but continuous state-space analogues of these theorems. Miloslav had been publishing on continuous state-space branching 
processes in very general settings (see Jiřina (1958), (1964a), (1966)) with his work culminating in the Rozpravy magnum opus. His eminence in the branching process area was manifested by his attendance at the renowned 5th Berkeley Symposium, and was corroborated by the translation of almost all his Russian-language papers into English.

ES wrote to him asking for an offprint of Jiřina (1958) and received it accompanied by Jiřina (1964a), (1966), and a courteous note from Miloslav dated 20th April 1967. This assistance led to the publication of the two papers Seneta and Vere-Jones (1968), (1969).

Flinders University in Adelaide had been established in 1966 and Miloslav began a twoyear Visiting Fellowship there in June 1968. His appointment was brought about through the agency of Dr Petr Mandl of the Charles University, Prague, who had visited ANU a little earlier. Miloslav was one of six Czechoslovak mathematicians to take up visiting appointments in Adelaide and Flinders Universities, a highly beneficial boost for mathematics in Adelaide. Whereas in Prague Miloslav had been surrounded by mathematicians with whom he could fruitfully converse about his esoteric field of mathematical probability, in Adelaide there was no one with whom he could usefully talk about his work. However, he was content to pursue his probabilistic research in isolation, both in his initial two years in Adelaide, and subsequently. He jointly authored a paper with John Darroch and John McDonald published in 1986, and another with John Darroch and Terry Speed published in 1988.

Shortly after Miloslav's arrival at Flinders University, Malcolm Quine, the first PhD student of ES at ANU, submitted with ES what became Quine and Seneta (1969) to the Australian Journal of Statistics. It was Malcolm's first paper. Miloslav in fact turned out to be the referee, as we found out when he called ES at ANU to check on a detail. Eventually, Miloslav was one of the examiners of Malcolm's PhD dissertation.

At the time of Miloslav's move to Adelaide, Jarmila senior was still working as a language teacher in the School of Languages in Prague. Jarmila junior, who had reluctantly agreed to accompany her parents to Adelaide for one year only, was still enrolled as a science student at Charles University and had to take some exams in September. Their planned departure was complicated by the Russian invasion of Czechoslovakia, on 21st August 1968. Normal life was badly disrupted and overseas air travel was not allowed from Prague airport. However, they did eventually leave their home country and they reached Adelaide on 10th September 1968 to join their husband and father.

At the completion of his two-year Visiting Fellowship in 1970 Miloslav was offered a Readership in the School of Mathematical Sciences of Flinders University, an offer that he happily accepted because the Russian invasion had removed any thoughts of his returning to work in Czechoslovakia. He held the Readership until his retirement at the end of 1992. Throughout all of his time at Flinders, Miloslav was a popular but exacting lecturer of second, third, and fourth year undergraduate courses in probability and statistics. A joint fourth year program was established with the larger Adelaide University, and for many years classes of good quality and satisfactory size were held. Sabbatical leave in 1972 took him to Sheffield, Athens, and Bavaria, and another in 1975 to Michigan State University.

Jarmila senior taught German for some years at Brighton High School while Jarmila junior put aside her initial reluctance to leave her home country and took a degree in Biological Sciences at Flinders University. She has since pursued a career in Medical Science and currently works in Surgical Pathology at Flinders Medical Centre.

The strength and depth of Miloslav's mathematical knowledge were an inspiration to his colleagues and to his students, and he was always generous with the time he devoted to passing on his understanding to others. He was an exceptional colleague, totally cooperative, unfailingly 
modest and a pillar of quiet sanity. These qualities were particularly valuable during the years 1978 to 1980 when he was Chairman of the School of Mathematical Sciences because he had to manage a protracted and divisive conflict over the examinations policy within the School. He had an amazingly good memory and a bottomless well of amusing reminiscences to draw from, many of which he told against himself. He brought with him from his European cultural background a profound appreciation of music, history, and the fine arts, and he regularly travelled from Adelaide to art gallery exhibitions in the other capital cities of Australia. During his forty two years in Australia he developed a passionate interest in Australian flora and fauna and amassed a large library of books on the plants, and birds and insects of his adopted country.

Miloslav died on 10th January 2011 after a protracted illness. He is survived by his wife, his daughter, and his two grandchildren, and is very sadly missed by all of the many individuals whose lives he enriched with his friendship.

The authors are deeply grateful for the information and advice provided by Miloslav's wife, Mrs Jarmila Jiřina.

Flinders University

JOHN DARROCH

University of Sydney

EugEne SEnEta

\section{References}

Gantmacher, F. R. (1953). Teoriya Matrits [Theory of Matrices]. Nauka, Moskva (in Russian).

Harris, T. E. (1951). Some mathematical models for branching processes. In Proc. 2nd Berkeley Symp. Math. Statist. Prob., 1950, University of California Press, Berkeley and Los Angeles, pp. 305-328.

Harris, T. E. (1963). The Theory of Branching Processes. Springer, Berlin.

Kolmogorov, A. N. (1938). Zur Lösung einer biologischen Aufgabe. Izv. NII Mat. Mekh. Tomsk. Univ. 2, 1-6. (Russianlanguage version: Izv. NII Mat. Mekh. Tomsk. Univ. 2, 7-12.)

Quine, M. P. and Seneta, E. (1969). A limit theorem for the Galton-Watson process with immigration. Austral. J. Statist. 11, 166-173.

SEneta, E. AND VerE-Jones, D. (1968). On the asymptotic behaviour of subcritical branching processes with continuous state space. Z. Wahrscheinlichkeitsth. 10, 212-225.

Seneta, E. AND Vere-Jones, D. (1969). On a problem of M. Jiřina concerning continuous state branching processes. Czechoslovak Math. J. 19(94), 277-283.

SeVAST'yanov, B. A. (1951). The theory of branching stochastic processes. Uspehi Mat. Nauk 6, 47-99 (in Russian).

YaGLOM, A. M. (1947). Certain limit theorems of the theory of branching random processes. Dokl. Akad. Nauk SSSR 56, 795-798 (in Russian).

\section{Publications of Miloslav Jiřina}

[1] JiŘINA, M. (1952). Sequential estimation of distribution-free tolerance limits. Czechoslovak Math. J. 2(77), 221232 (in Russian). (Correction: 3(78) (1953), 283.) English translation: in Selected Translations in Mathematical Statistics and Probability, Vol. 1, Institute of Mathematical Statistics, Providence, RI, 1961, pp. 145-155.

[2] JIŘInA, M. (1954). Conditional probabilities on strictly separable $\sigma$-algebras. Czechoslovak Math. J. 4(79), 372380 (in Russian). English translation: in Selected Translations in Mathematical Statistics and Probability, Vol. 2, Institute of Mathematical Statistics, Providence, RI, 1962, pp. 79-86.

[3] Jiřina, M. AND Nedoma, J. (1956). Minimax solution of sampling inspection plan. Apl. Mat. 1, $296-314$ (in Czech).

[4] JIŘInA, M. (1957). The asymptotic behaviour of branching stochastic processes. Czechoslovak Math. J. 7(82), 130-153 (in Russian). English translation: in Selected Translations in Mathematical Statistics and Probability, Vol. 2, Institute of Mathematical Statistics, Providence, RI, 1962, pp. 87-107.

[5] Jı̌̌ınA, M. (1958). Stochastic branching processes with continuous state space. Czechoslovak Math. J. 8(83), 292-313.

[6] JIŘINA, M. (1959). On regular conditional probabilities. Czechoslovak Math. J. 9(84), 445-451. 
[7] JIŘINA, M. (1962). Ordinary differential and difference equations with random coefficients and random righthand side. Czechoslovak Math. J. 12(87), 457-474 (in Russian).

[8] JIŘINA, M. (1963). Harmonisable solutions of ordinary differential equations with random coefficients and random right-hand side. Czechoslovak Math. J. 13(88), 360-371 (in Russian).

[9] JIŘInA, M. (1964a). Branching processes with measure-valued states. In Trans. 3rd Prague Conf. Information Theory, Statist. Decision Functions, Random Processes (Liblice, 1962), Publ. House Czech. Acad. Sci., Prague, pp. 333-357.

[10] Jǐ̌ınA, M. (1964b). A note on infinitely divisible and nonnegative distributions. Časopis Pěst. Mat. 89, 347-353 (in Czech).

[11] JiŘınA, M. (1966). Asymptotic behaviour of measure-valued branching processes. Rozpravy Československé Akad. Věd. 76, no. 3, 55pp.

[12] JIŘInA, M. (1967). General branching processes with continuous time parameter. In Proc. 5th Berkeley Symp. Math. Statist. Prob. (Berkeley, 1965/66), Vol. II, Part 1, University of California Press, Berkeley, pp. 389-399.

[13] JiřınA, M. (1969). On Feller's branching diffusion processes. Časopis Pěst. Mat. 94, 84-90, 107.

[14] Jiřısa, M. (1970). A simplified proof of the Sevastyanov theorem. Ann. Inst. H. Poincaré Sect. B. (N.S.) 6, 1-7.

[15] JIŘInA, M. (1971). Diffusion branching processes with several types of particles. Z. Wahrscheinlichkeitsth. 18, 34-46.

[16] JIŘINA, M. (1972). Convergence in distribution of random measures. Ann. Math. Statist. 43, 1727-1731.

[17] JiŘınA, M. (1973/74). A theorem on breakage-mechanism-branching processes. Z. Wahrscheinlichkeitsth. 28, 179-187.

[18] Jǐ̌ına, M. (1976a). Extinction of non-homogeneous Galton-Watson processes. J. Appl. Prob. 13, $132-137$.

[19] JIŘINA, M. (1976b). On the asymptotic normality of Kendall's rank correlation statistic. Ann. Statist. 4, $214-215$.

[20] Jiřina, M. (1978). A biased roulette. Ann. Inst. H. Poincaré Sect. B. (N.S.) 14, 1-23.

[21] JIŘINA, M. (1982a). Interpolation of completely monotone functions. Monatsh. Math. 94, 103-107.

[22] JiŘına, M. (1982b). Limit theorems for samples from a finite population. J. Austral. Math. Soc. Ser. A 32, 318-327.

[23] Darroch, J., Jiǩina, M. And McDonald, J. (1986). The sum of finite moving average processes. J. Time Ser. Anal. 7, 21-25.

[24] JIŘINA, M. (1987a). Limit theorems for sums of independent random variables observed on a finite population. Indian J. Math. 29, 65-83.

[25] JIŘINA, M. (1987b). Limit theorems for triangular arrays under a relaxed asymptotic negligibility condition. J. Austral. Math. Soc. Ser. A 42, 117-128.

[26] Darroch, J. N., JiŘInA, M. ANd Speed, T. P. (1988). Sampling without replacement: approximation to the probability distribution. J. Austral. Math. Soc. Ser. A 44, 197-213. 